\title{
CEREBRAL TUMOUR CAUSING HYDROCEPHALUS WITH FILLING DEFECT OF THE TEMPORAL HORN
}

\author{
BY
}

\section{COLIN A. GLEADHILL}

\author{
From the Department of Surgical Neurology, Bangour Hospital, West Lothian, Scotland
}

The important diagnostic significance of filling defects of the temporal horn is well illustrated in the two cases here described. Both patients were middle-aged men with few neurological signs but with raised intracranial pressure and a moderate increase in cerebrospinal fluid cells and protein. In both cases the local cerebral symptomatology indicated a diencephalic disturbance. Ventriculograms showed extensive internal hydrocephalus with no significant lateral shift of midline structures but with filling defects and dislocation of the temporal horn. Although there was hydrocephalus, there was sufficient patency of the fluid pathways to permit the air introduced into the lateral ventricles to fill the fourth ventricle and cisterna magna. In Case 1 (Figs. 1, 2, 3) the deformity of the temporal horn is easily seen ; in Case 2 (Figs. 7 and 8) it is minimal.

Post-mortem examination in both cases revealed ependymoblastoma, which had deeply invaded the brain without causing much displacement. There were numerous secondary deposits throughout the walls of ventricular cavities, with the primary growth in relation to the left temporal horn in each instance, causing the filling defects. Some of the seedlings had caused partial obstruction of cerebrospinal fluid circulation. The deposits which caused obstruction were too small to have been detectable by pneumography.

\section{Case Histories}

Case 1.-A man aged 47 years was admitted to hospital on Sept. 11, 1944. For five months before admission he had suffered progressively from headache and from mental deterioration. On admission there was slight papillodema, tremor of the right hand, and relatively rapid fatigue of the right abdominal reflex. Lumbar puncture revealed a pressure of $210 \mathrm{~mm}$. with normal dynamics. The cerebrospinal fluid was yellow and contained 30 cells per c.mm. (lymphocytes and polymorphs) and $100 \mathrm{mg}$. of total proteins per $100 \mathrm{c.cm}$. Ventriculography showed slight dilatation of the lateral ventricles. The significance of a slight filling defect and irregularity of outline of the floor of the left lateral ventricle was not then appreciated.
Within the next year there occurred further mental deterioration, epileptic attacks, increased tremor, and more advanced papillœdema. A second ventriculogram at this time showed a greater degree of symmetrical dilatation of the ventricles than before, and the filling defect of the atrium and temporal horn of the left lateral ventricle (Figs. 1, 2, 3) already mentioned. A rounded dense filling defect thought to represent a tumour in the cerebellar vermis was also noted (Fig. 3X). Accordingly a suboccipital decompression was carried out in order to relieve the progressive hydrocephalus. Later, despite this procedure, increasing hydrocephalus made it necessary to carry out a third ventriculostomy. Mental deterioration and epilepsy progressed, and the patient died two months later.

Post-mortem examination showed an ependymoblastoma in the left thalamus which had replaced, without displacing, cerebral tissue (Fig. 4). There were multiple secondary tumour seedlings throughout the walls of the ventricular cavities, particularly in the left temporal horn (Figs. 4 and 5). The hydrocephalus was due to a larger seedling on the superior cerebellar vermis (Fig. 6).

Case 2.-A man aged 59 years was admitted to hospital on Oct. 3, 1947. For five months before admission he had been suffering from increasing headache and mental deterioration. Examination on admission revealed moderate papillœdema, tremor, and hypertonia of all four limbs. Lumbar puncture showed a pressure of $90 \mathrm{~mm}$. (lumbar puncture had been performed just before admission, when the pressure was said to be raised), normal dynamics and yellow, clear fluid containing 50 cells per c.mm. ( 70 per cent. lymphocytes, 30 per cent. polymorphs) and $220 \mathrm{mg}$. of total proteins per $100 \mathrm{c.cm}$.

Ventriculography revealed a marked dilatation of the lateral and third ventricles without gross displacement, with a constriction at the upper third of the aqueduct (Fig. 8). The severe internal hydrocephalus due to obstruction of the aqueduct was treated by implacement of ventriculo-cisternal tubes (Torkildsen's operation). The significance of the upward elevation and filling defect of the floor of the temporal horn of the left ventricle (Figs. 7 and 8) was not appreciated. The evidence of previous hæmorrhage and of excess protein in the cerebrospinal fluid and the cause of the aqueduct obstruction remained unexplained. The patient, who was very ill, did not long survive the operation for relief of the hydrocephalic complication. 

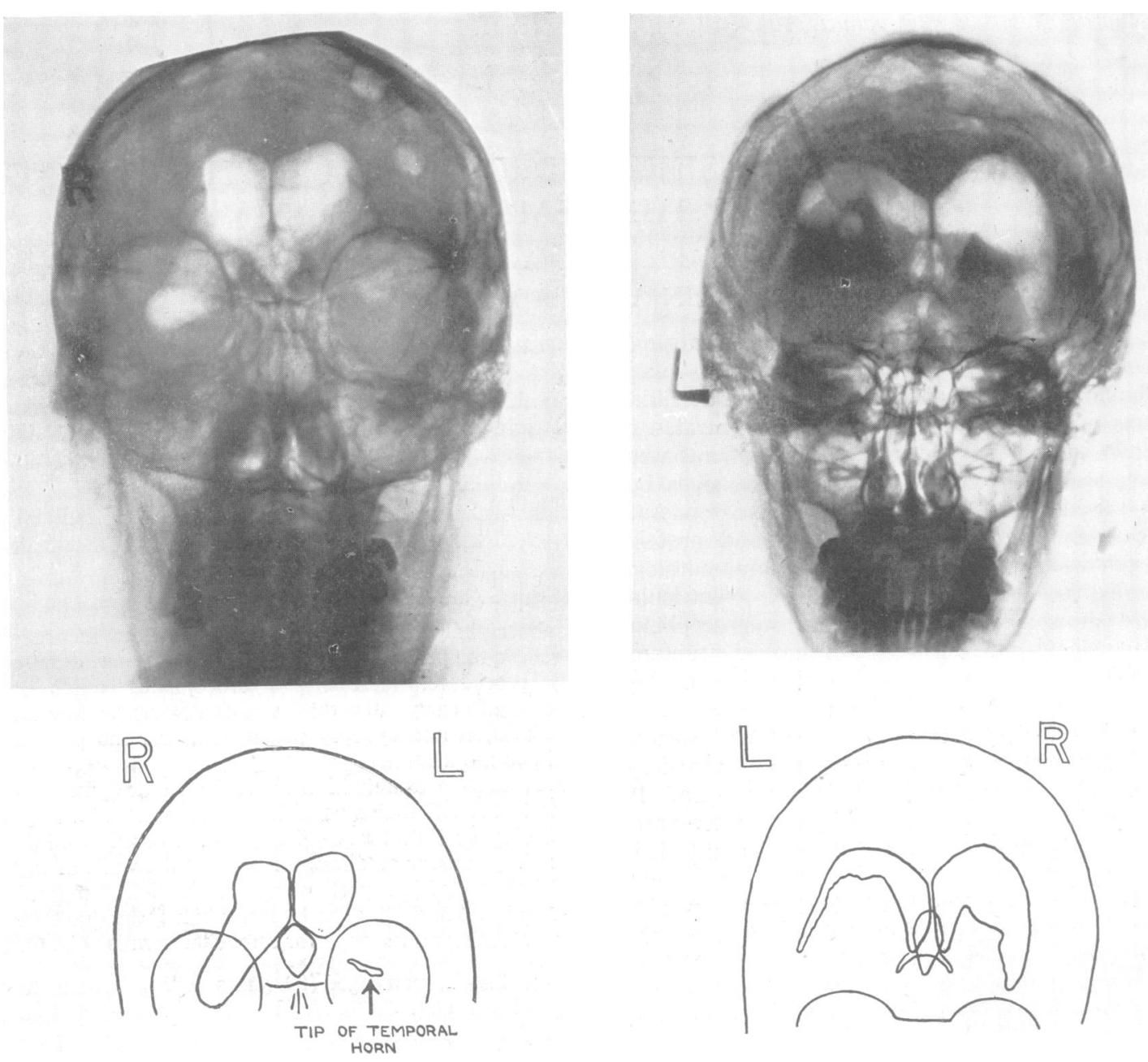

FIG. 1 (and Key).-Antero-posterior view shows severe hydrocephalus, practically no lateral shift, but filling defect and upward dislocation of left temporal horn (Case 1).

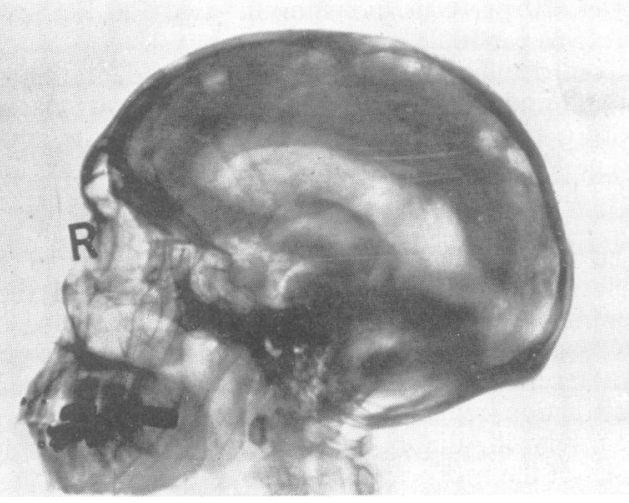

Fig. 2 (and Key).-Postero-anterior view shows vez slight shift of septum with filling defect of atriugh and filling defect and upward dislocation of left temporal horn (Case 1).

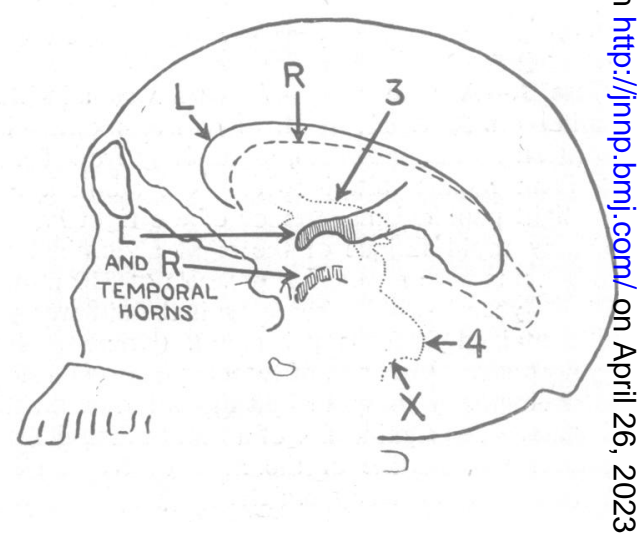

Fig. 3 (and Key).-Left side up. Lateral view shows filling defect and upward dislocation of left temporal horn. $\mathrm{L}, \mathrm{R}, 3$, and $4=$ outlines of left, right, third, and fourth ventricles. $\mathrm{X}=$ filling'defect in fourth (Case 1). 

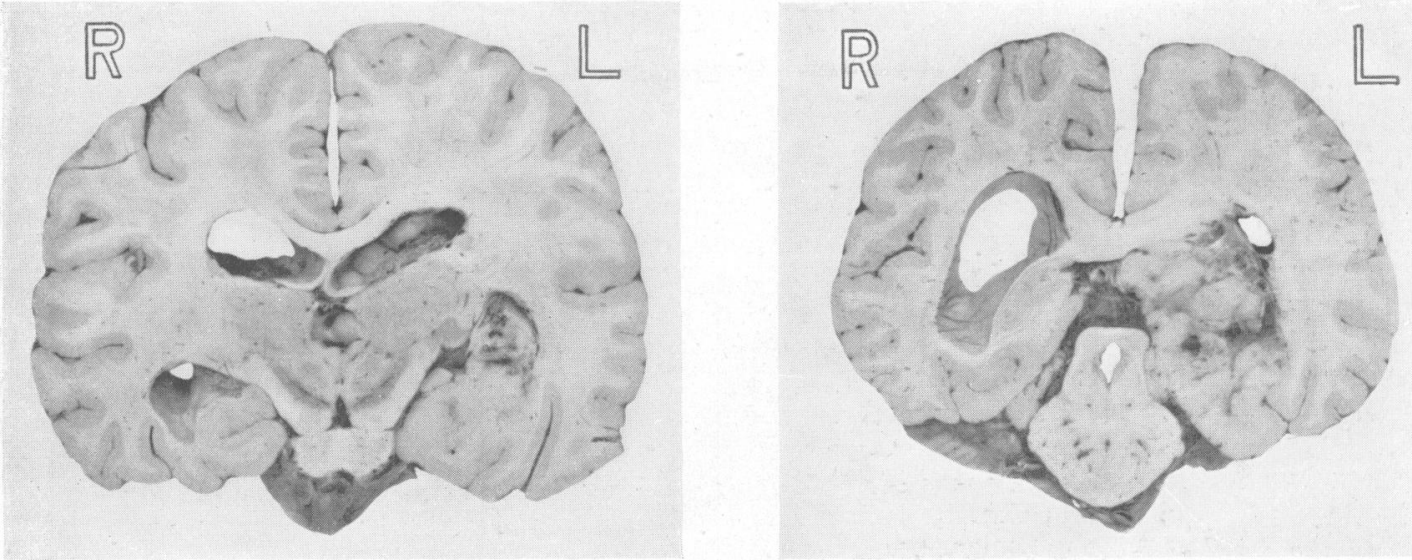

FIGS. 4 and 5.-Post-mortem sections showing body and 'temporal horn studded with tumour nodules, and replacement of cerebral tissue by tumour (Case 1).

FIG. 6.-Section showing tumour at superior cerebellar vermis (Case 1).
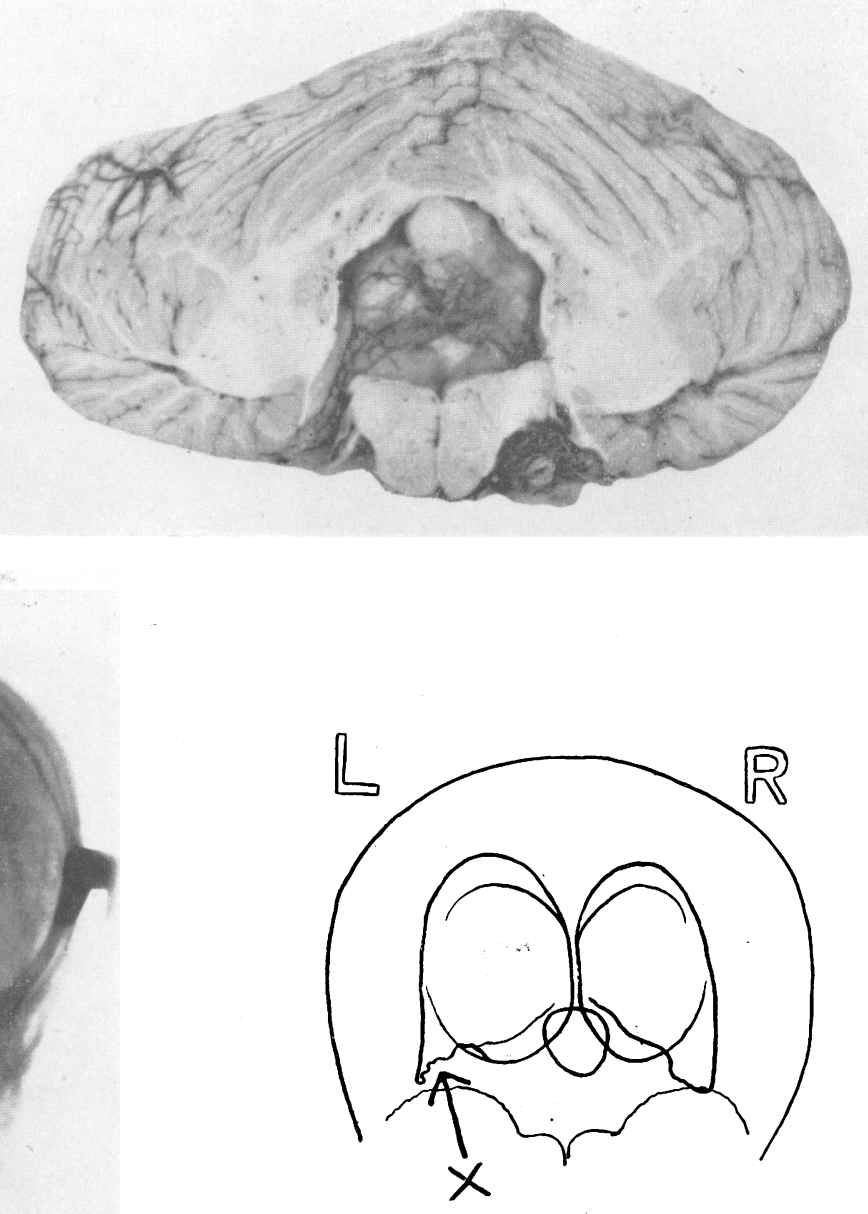

FIG. 7 (and Key).-Postero-anterior view shows absence of lateral shift and gross hydrocephalus symmetrical save for filling defect and slight upward dislocation of left temporal horn (X) (Case 2). 

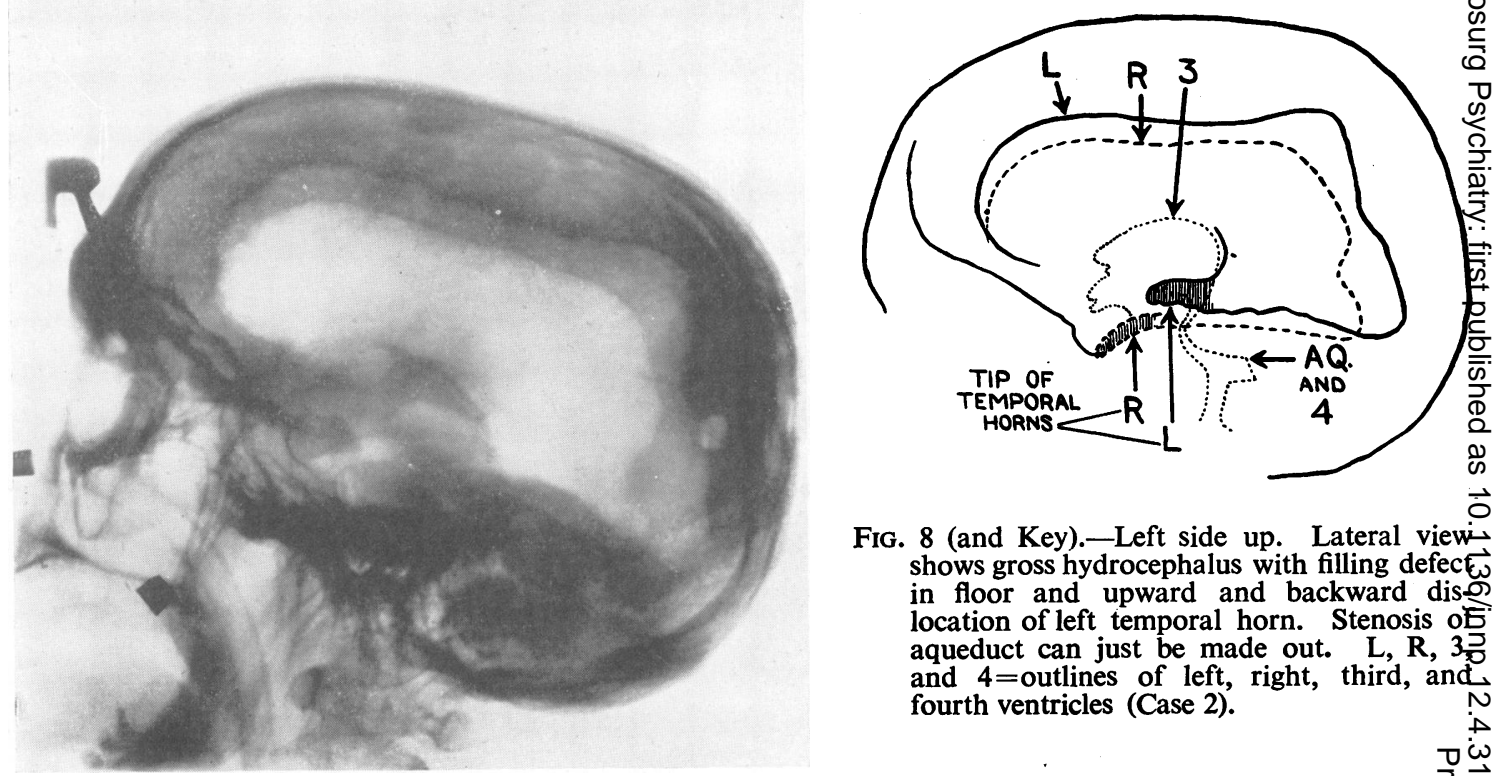

Fig. 8 (and Key).-Left side up. Lateral viewshows gross hydrocephalus with filling defect in floor and upward and backward dise location of left temporal horn. Stenosis ô: aqueduct can just be made out. $L, R, 3 \frac{2}{0}$ and $4=$ outlines of left, right, third, and fourth ventricles (Case 2).
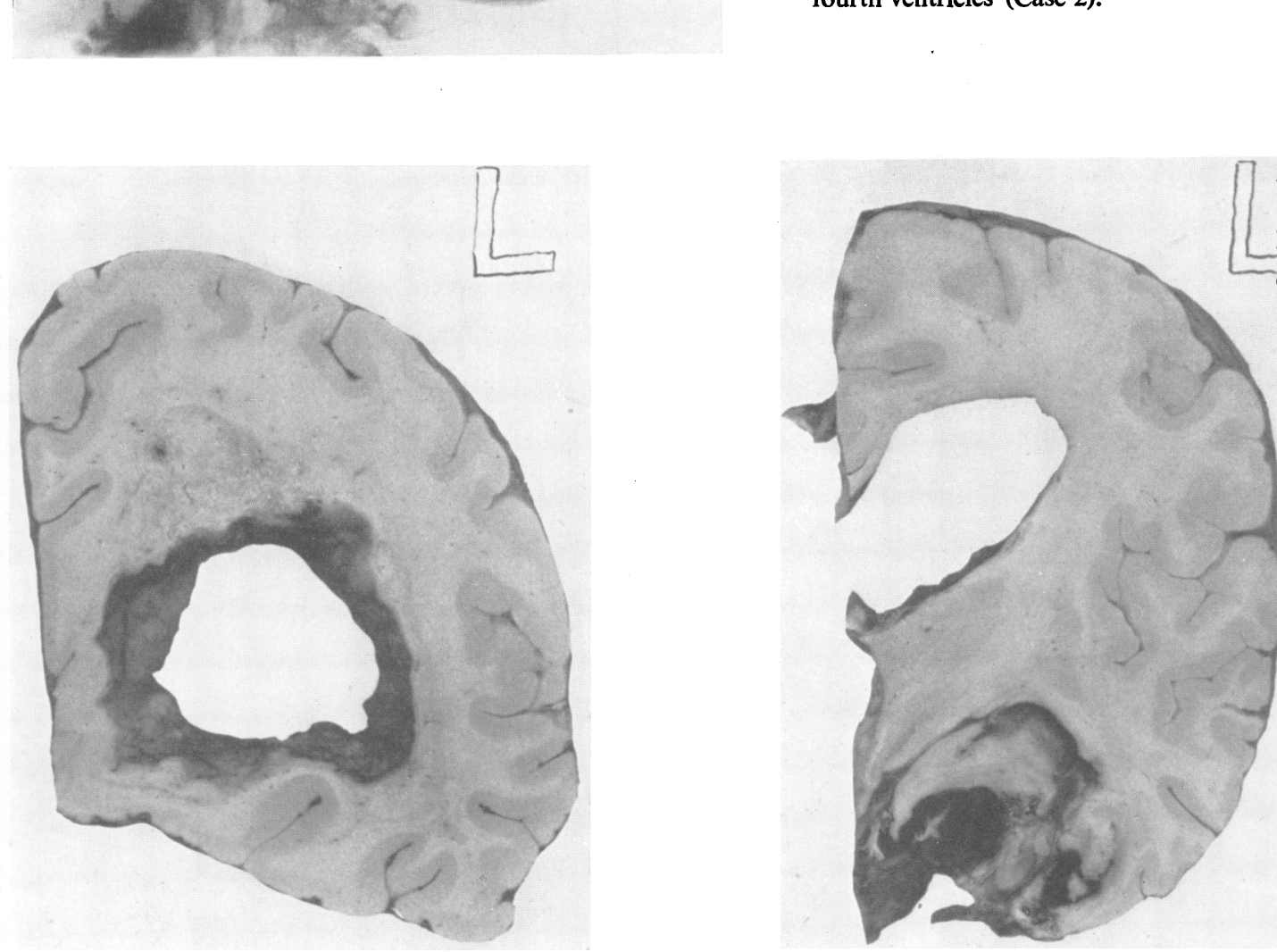

Figs. 9 and 10.-Sections showing body of lateral ventricle studded with tumour and similar deposits floor of temporal horn (Case 2). 


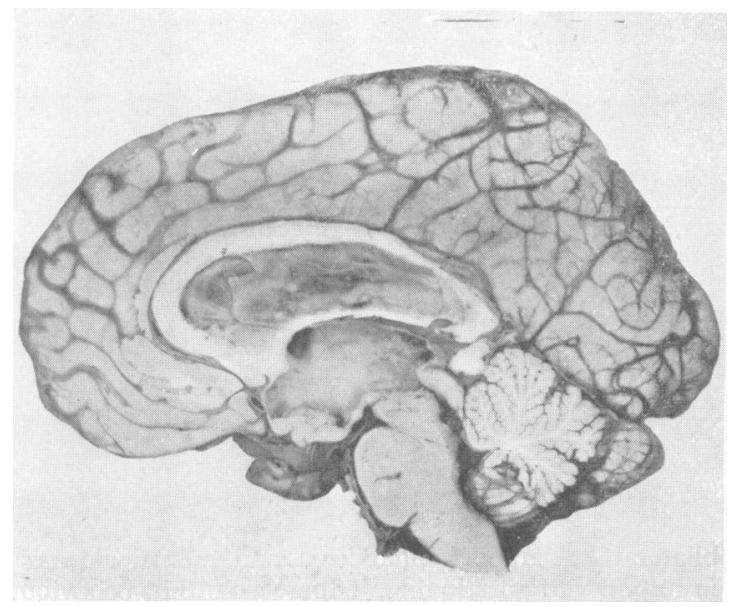

FIG. 11.-Section showing obstruction of lumen of aqueduct of Sylvius by tumour (Case 2).

Post-mortem examination revealed a small ependymoblastoma slightly indenting the floor of the temporal horn of the left ventricle. There were small seedling tumours throughout the walls of the ventricular cavities (Figs. 9 and 10). Some of these in the aqueduct were responsible for the fluid obstruction there (Fig. 11). Death was due to invasion of the floor of the fourth ventricle by other seedlings (Fig. 11).

\section{Discussion}

The diagnosis of these neoplasms may be facilitated and the significance of their secondary effects correctly interpreted, if it is borne in mind that the following features may occur in association :

1. Replacement by tumour tissue without displacement may. occur, and there may be thus no shift of midline structures even in advanced cases.

2. A gross internal hydrocephalus due to obstruction of the cerebrospinal fluid circulation by seedlings may so dominate the picture that attention may be focused upon the aqueduct and posterior fossa while the supratentorial neoplasm is not noticed.

3. Deliberate search of ventriculograms, if the possibility of filling defect is borne in mind, may reveal plaques and nodules of tumour in the walls of the ventricles.

4. There is usually a moderate increase in the cellular and protein content of the cerebrospinal fluid in the presence of intraventricular ependymoblastoma.

A complete diagnosis may therefore be missed through failure to search for minor filling defects and distortions in the temporal horns in the presence of an apparently symmetrical hydrocephalus. Since we have found these ependymoblastomas highly radiosensitive, their diagnosis is no mere academic exercise but is of great practical importance for adequate treatment of the patients.

The ventriculograms reproduced were from antero-posterior, postero-anterior, and right and left lateral stereoscopic projections. Complete air replacement was first obtained by sitting the patient up and introducing air through both ventricular catheters whilst allowing fluid to escape from a lumbar needle, until air appeared at the latter. The position of the head was suitably altered during the procedure to ensure complete displacement of fluid from the ventricles. Although it was not used in these two cases, and although the abnormalities are sufficiently shown by the method here described, the special filling technique and projections described by Lindgren would probably provide additional information in such cases.

In the series of 137 cases of temporal horn deformity reviewed by Lindgren (1948) the particular syndrome described here does not occur. Certain tumours in his series caused no shift of midline structures, thus " . . . by neurinomas from gasserian ganglion and by pterion tumours growing en plaque, septum need not be dislocated. This is also true of the gliomas. Thus in five cases ... there has been no displacement of the septum. The same applied to the one case of metastasis and the case of chronic juvenile subdural hæmatoma." He further states, "The pathological process could not have been demonstrated, had not the temporal horn been examined," a statement the value of which is well supported by experience of the two cases here described.

Lindgren's cases of neoplasm without displacement of the septum showed a displacement of the temporal horn. In only three of them were irregularities of the wall present ; these were gliomas. In only one of his cases was hydrocephalus present, and to a minor degree only. We have not previously encountered a description of any comparable cases. in which a gross internal hydrocephalus is caused by' tumour seedlings, and in which the parent-tumour could be recognized by a critical study of the temporal horn by pneumography.

\section{Summary}

A description of two cases of ependymoblastoma with certain ventriculographic appearances.

My thanks are due to Professor Norman M. Dott for his permission to publish these cases and for his advice and criticism in the preparation of this paper.

\section{REFERENCE}

Lindgren, E. (1948). Acta radiol. Supplement 69. 